\title{
Estratégias de enfrentamento para manutenção da saúde mental do trabalhador em tempos de Covid-19: Uma Revisão Integrativa
}

\author{
Strategies for worker's mental health maintenance in \\ Covid-19 times: An Integrative Review
}

\section{Rodrigo Barbosa Nascimento ${ }^{1}$ (i) Iasmin Fênix Lira de Araújo $^{2}$ (1) Érika dos Santos Vieira ${ }^{3}$ (1) Ana Carolina de Araujo Oliveira 4 (1) Roberta Lima Machado de Souza Araújo 5 (1)}

\footnotetext{
${ }^{1}$ Autor para correspondência. Universidade Salvador (Feira de Santana). Bahia, Brasil. nascimentolag@gmail.com ${ }^{2-4}$ Universidade Salvador (Feira de Santana). Bahia, Brasil. ifla.1985@gmail.com, erikavieiras@outlook.com, caarol-araujo1@hotmail.com ${ }^{5}$ Universidade Salvador e Universidade Estadual de Feira de Santana (Feira de Santana). Bahia, Brasil. robertamachado.psi@gmail.com
}

RESUMO | OBJETIVO: Apresentar evidências científicas de possíveis estratégias que podem ser empregadas em trabalhadores para minimização de sofrimento psíquico decorrente do contexto pandêmico. MÉTODO: Durante o mês de maio e junho de 2020 realizou-se uma revisão integrativa da literatura científica acerca da temática em questão, sendo utilizados os descritores indexados no DeCS: estratégias de enfrentamento; infecções por coronavírus; saúde mental e trabalhadores. Para realizar a pesquisa, os descritores foram combinados nas bases de dados Pepsic, Pubmed e Scielo. RESULTADOS: Foi possível identificar as seguintes estratégias de enfrentamento de caráter preventivo: medidas de identificação precoce dos sintomas mentais, medidas regulares de descanso e treinamento de pessoal. Assim como, foi possível evidenciar medidas de promoção em saúde mental aos trabalhadores, tais como: utilização de primeiros socorros psicológicos; participação de grupos terapêuticos; gerenciamento de crises. E, na área da reabilitação em saúde mental: utilização de técnicas de meditação e mindfulness, tanto para serem executadas por profissionais de saúde, no âmbito organizacional, quanto por ações governamentais. CONCLUSÃO: Considera-se que a informação de técnicas e práticas psicológicas voltadas a saúde psíquica do trabalhador possa contribuir na identificação e controle dos riscos psicossociais e colaborar para o desenvolvimento no campo da Saúde Pública em relação aos processos de saúde-doença dos trabalhadores, em especial, dos agravos a saúde mental derivados da pandemia.

PALAVRAS-CHAVE: Estratégias de enfrentamento. Infecções por Coronavírus. Saúde mental. Trabalhadores.
ABSTRACT | OBJECTIVE: To present scientific evidence of possible strategies that can be used in workers to minimize psychological distress resulting from the pandemic context. METHOD: During the month of May and June 2020, an integrative review of the scientific literature was carried out on the subject in question, using the descriptors indexed in the DeCS: coping strategies; coronavirus infections; mental health and workers. To carry out the research, the descriptors were combined in the Pepsic, Pubmed and Scielo databases. RESULTS: It was possible to identify the following preventive coping strategies: measures for early identification of mental symptoms, regular measures of rest and training of personnel. As well, it was possible to highlight measures to promote mental health to workers, such as: use of psychological first aid; participation of therapeutic groups; crisis management. And, in the area of mental health rehabilitation: use of meditation and mindfulness techniques, both to be performed by health professionals, at the organizational level, as well as by government actions. CONCLUSION: It is considered that the information on psychological techniques and practices aimed at the worker's psychological health can contribute to the identification and control of psychosocial risks and collaborate for the development in the field of Public Health in relation to the workers' health-illness processes, in particular, of the mental health problems resulting from the pandemic

KEYWORDS: Adaptation. Psychological. Coronavirus Infections. Mental Health. Occupational Groups. 


\section{Introdução}

As estratégias de enfrentamento, também conhecidas como coping, são respostas cognitivas em forma de pensamentos ou ações que visam proteger a saúde mental e física dos efeitos danosos causados pelo estresse (Folkman, 2012). Conforme sinalizam Ramos, Enumo e De Paula (2015) em seus estudos sobre as abordagens de enfrentamento propostas por Lazarus e Folkman (1984), existem duas modalidades de coping, relacionadas aos recursos pessoais de cada indivíduo, são elas: o coping focado na emoção, no qual o sujeito avalia uma situação com base no alívio emocional, buscando administrar a forma como se sente frente ao contexto e não a mudança do problema em si; e o coping centrado no problema, relacionado ao gerenciamento da situação objetiva. Deste modo, ao serem evidenciados episódios estressores, constata-se um esgotamento de recursos mentais, sociais e físicos, o que acarreta em sofrimento psicológico, fazendo-se necessários mecanismos que auxiliem na redução dos impactos que agravam o estresse crônico, bem como, na promoção de bem-estar mental (Folkman, 2012).

Em situações de crises e emergências, estratégias de enfretamentos extrínsecas fazem-se mister, visto que nem todos indivíduos possuem repertório de enfrentamento suficiente para lidar com contextos de estresses e traumas, e até mesmo aqueles que o possuem, podem ter suas estratégias reduzidas em virtude de situações adversas. Assim, os recursos externos atuam como um suporte psicológico relevante para que novas possibilidades de enfrentamento sejam adquiridas nesses contextos (Stone, 2020).

Em 2020 ao ser declarada como pandemia pela OMS, a COVID-19, doença causada pelo novo vírus RNA da família dos beta-coronavírus, nomeado como SARSCoV-2 (Guan et al., 2020), gerou uma crise mundial de grande impacto social e econômico, especialmente por conta de sua facilidade de transmissão. De acordo com o Ministério da Saúde (2020), este vírus tem se manifestado desde um simples resfriado até quadros mais graves como a pneumonia severa. Esse vírus tem como sintomas principais a dificuldade respiratória, febre e tosse, embora Huang et al. (2020) ressalte a possibilidade de apresentarem fadiga, dor de cabeça, produção de escarro e diarreia em menor proporção.
Além dos impactos na saúde, são evidentes os efeitos no contexto social, em especial no mundo do trabalho. A adoção de medidas como distanciamento e isolamento social dificultou a realização das atividades laborais o que influenciou na perda de renda devido ao fato de não poder trabalhar ou ser demitido. Ainda sobre esses impactos, observa-se alterações da rotina de sono e do nível de concentração nas atividades cotidianas; sentimentos de desesperança; tédio ao longo do dia; procrastinação e solidão; além de raiva e frustração ocasionadas pela perda de autonomia e liberdade pessoal (Costa, 2020).

Com relação à saúde mental do trabalhador no Brasil, em um estudo realizado pela Vigilância aos Agravos a Saúde do Trabalhador entre os anos de 2006 e 2017 estima que os principais diagnósticos em saúde mental vinculados ao setor de trabalho são reação ao "estresse" grave e transtornos de adaptação (47\%), episódios depressivos (24\%), transtornos ansiosos (17\%), transtorno depressivo recorrente (7\%), entre outros (5\%) (Centro de Referência em Saúde do Trabalhador, 2019). Considerando esses dados e observando toda a possibilidade de prejuízo a saúde psicológica do trabalhador, nas circunstâncias pandêmicas atuais, a preservação da saúde mental dos trabalhadores é tarefa essencial (Fiho et al., 2020), sobretudo com o propósito de conter os avanços de problemas mentais já comumente presentes no mundo do trabalho.

De acordo com Ornell et al. (2020), os profissionais do campo da saúde que permanecem em suas atividades apresentam, dentre várias manifestações, risco aumentado de contaminação, sensação de perda do mundo presumido, posto que ainda não existem protocolos específicos para lidar com o contexto de crise, assim como é frequente o sofrimento devido ao luto antecipatório vivenciado. Estas variáveis aumentam sobremaneira o risco de manifestação de sofrimento mental e/ou transtornos mentais graves e persistentes relacionados as atividades laborais exercidas, conforme explicitado por Ho, Chee \& Ho, R. (2020) e Zhang et al. (2020) ao ressaltarem a possiblidade do desenvolvimento de Transtorno do Estresse Pós Traumático, Depressão e Ansiedade.

Segundo Lazarus e Folkman (1984), a percepção acerca do enfrentamento não deve ser comparada a uma espécie de domínio sobre o ambiente externo, principalmente, porque muitas fontes que proporcionam 
alterações emocionais não podem ser controladas, portanto, o enfrentamento eficaz nessas condições é aquele que permite à pessoa tolerar, minimizar, aceitar ou ignorar o que não pode ser controlado. Dito isto, tal acepção converge com o contexto atual da pandemia por COVID-19, visto que ela transcende as possibilidades de respostas emocionais e/ou comportamentais dos sujeitos.

Assim, quando o sujeito não consegue vivenciar a situação exposta com seus próprios atributos psíquicos, utilizar-se de estratégias de enfrentamento extrínsecas tornam-se fundamentais para suporte neste momento adverso, auxiliando no desenvolvimento de novos recursos emocionais e comportamentais. Como estratégias externas podem ser mencionadas o exercício de autocuidado e o fomento de um ambiente psicossocial seguro aos trabalhadores a fim de que estes possam lidar de maneira mais saudável com os efeitos da pandemia, minimizando os impactos de um ambiente com elevado nível de estresse e as demandas de uma situação sem precedentes, num cenário de muitas incertezas e mortes (Fiho et al., 2020; Stone, 2020).

A partir de uma revisão integrativa, este artigo tem como objetivo sistematizar as principais estratégias e medidas associadas a saúde mental do trabalhador, compreendendo a sua relevância no momento atual por abordar recursos que podem auxiliar o trabalhador no enfrentamento dos efeitos da pandemia. Para tanto, foi realizada nos meses de maio e junho uma revisão integrativa dos artigos publicados sobre esta temática.

\section{Método}

Esta revisão integrativa tem como objetivo apresentar evidências científicas acerca das principais estratégias de enfrentamento que estão sendo recomendadas e utilizadas para verificação da situação de saúde mental de trabalhadores em contexto pandêmico decorrente da COVID-19, no que tange à prevenção de sofrimento psíquico, promoção de saúde mental e instrumentos para detecção de sofrimento psíquico em trabalhadores.
Esse tipo de revisão possui caráter mais ampliado em pesquisas de literatura, posto que permite a inclusão de estudos tanto observacionais e experimentais, quanto estudos de revisão (Souza et al., 2010).

O primeiro passo para o desenvolvimento deste estudo foi a construção da pergunta de investigação: "Quais as estratégias têm sido recomendadas e utilizadas em contexto pandêmico como suporte a saúde mental dos trabalhadores?". Posteriormente, foi feito um levantamento no DeCS (Descritores em Ciências da Saúde), utilizando os descritores: Estratégias de enfrentamento; Infecções por Coronavírus; Saúde mental; Trabalhadores. Ademais, realizaram-se os seguintes cruzamentos: "Infecções por Coronavírus" and "Saúde mental" or "Estratégias de enfrentamento" or "Trabalhadores". O levantamento da amostra para esta pesquisa foi efetuado nas bases de dados SciELO, PubMed e PepsiC, no período de maio e junho de 2020.

A eleição dos estudos deu-se por meio dos seguintes critérios de inclusão: artigos originais, estudos de revisão, relatos de experiência, pesquisa aplicada e estudos de coorte transversal que apresentassem medidas direcionadas a saúde mental do trabalhador durante a pandemia da COVID-19, não havendo restrição de idiomas e nem à classe trabalhadora. Como critérios de exclusão, optou-se por excluir artigos que não abordassem a saúde mental do trabalhador ou que apesar de direcionados à saúde mental dos trabalhadores, não manifestassem medidas e estratégias de prevenção, promoção ou avaliação da saúde psíquica dos profissionais, bem como estudos sem clareza metodológica e com objetivo e conclusão não definidos.

No processo de busca foram encontrados inicialmente 447 artigos, dos quais 403 foram excluídos após a leitura dos títulos e verificação daqueles que não faziam menção à saúde mental. Seguidamente, realizou-se leitura dos resumos dos 44 artigos restantes, sendo excluídos 20 que não citavam a saúde mental dos trabalhadores. Os 24 estudos foram lidos integralmente, sendo excluídos 04 após análise da qualidade metodológica dos estudos, isto é, aqueles que não apresentavam medidas de prevenção, promoção ou avaliação da saúde mental, bem como indicação do objetivo e consideração final consonante com o intuito do estudo. 
Tabela 1. Demonstrativos das categorias elencadas por base de dados.

\begin{tabular}{|c|c|c|c|c|c|c|c|}
\hline $\begin{array}{c}\text { Base de } \\
\text { Dados }\end{array}$ & $\begin{array}{c}\text { Artigos } \\
\text { Recuperad } \\
\text { os }\end{array}$ & $\begin{array}{c}\text { Artigos } \\
\text { excluídos } \\
\text { após } \\
\text { aplicação } \\
\text { dos } \\
\text { critérios de } \\
\text { exclusão } \\
1^{\text {aaetapa }}\end{array}$ & $\begin{array}{l}\text { Artigos } \\
\text { após } \\
\text { aplicação } \\
\text { dos } \\
\text { critérios de } \\
\text { exclusão } \\
1^{\text {aaetapa }}\end{array}$ & $\begin{array}{l}\text { Artigos } \\
\text { excluídos } \\
\text { após } \\
\text { aplicação } \\
\text { dos } \\
\text { critérios de } \\
\text { exclusão } \\
2^{\text {aetapa. }}\end{array}$ & $\begin{array}{l}\text { Artigos } \\
\text { após } \\
\text { aplicação } \\
\text { dos } \\
\text { critérios de } \\
\text { exclusão } \\
2^{\text {aetapa. }}\end{array}$ & $\begin{array}{l}\text { Artigos } \\
\text { excluídos } \\
\text { após } \\
\text { aplicação } \\
\text { dos } \\
\text { critérios de } \\
\text { exclusão } \\
3^{\text {aetapa. }}\end{array}$ & $\begin{array}{l}\text { Artigos } \\
\text { após } 3^{a} \\
\text { etapa. }\end{array}$ \\
\hline Scielo & 65 & 50 & 15 & 9 & 06 & 1 & 5 \\
\hline PubMed & 382 & 353 & 29 & 11 & 18 & 3 & 15 \\
\hline PepsiC & 0 & 0 & 0 & 0 & 0 & 0 & 0 \\
\hline Total & 447 & 403 & 44 & 20 & 24 & 04 & 20 \\
\hline
\end{tabular}

Fonte: Os autores (2020).

Quadro 1. Avaliação final dos estudos incluídos de acordo com a enumeração do Quadro 2 (continua)

\begin{tabular}{|c|c|c|c|}
\hline MÉTODO & PARTICIPANTES & OBJETIVO & CONCLUSÃO \\
\hline $\begin{array}{l}\text { 1. Revisão } \\
\text { sistemática } \\
\text { baseada nos } \\
\text { protocolos de } \\
\text { atendimento a } \\
\text { paciente com } \\
\text { COVID-19, } \\
\text { documentos da } \\
\text { OPAS e artigos } \\
\text { científicos. }\end{array}$ & $x$ & $\begin{array}{l}\text { Sintetizar ações para a } \\
\text { gestão da segurança } \\
\text { psicológica dos profissionais } \\
\text { de saúde. }\end{array}$ & $\begin{array}{l}\text { Os profissionais de saúde precisam ser } \\
\text { objeto da gestão da segurança psicológica, } \\
\text { visto os problemas psicológicos que os } \\
\text { estudos encontrados fazem menção. }\end{array}$ \\
\hline $\begin{array}{l}\text { 2.Estudo de } \\
\text { Coorte- } \\
\text { Transversal }\end{array}$ & $\begin{array}{l}\text { ETAPA 1: } \\
92 \text { participantes } \\
\text { ETAPA 2: } \\
10 \text { participantes } \\
\text { ETAPA 3: } \\
58 \text { participantes } \\
\text {. }\end{array}$ & $\begin{array}{l}\text { Desenvolver e avaliar pacote } \\
\text { de aprendizado digital } \\
\text { relacionados ao bem-estar } \\
\text { psicológico dos funcionários } \\
\text { de saúde do Reino Unido. }\end{array}$ & $\begin{array}{l}\text { O pacote foi considerado útil, significativo } \\
\text { e adequado as necessidades psicológicas } \\
\text { dos profissionais de saúde como } \\
\text { complemento as suas estratégias de bem- } \\
\text { estar. }\end{array}$ \\
\hline $\begin{array}{l}\text { 3. Revisão } \\
\text { Bibliográfica }\end{array}$ & $x$ & $\begin{array}{l}\text { Revisão dos estudos sobre o } \\
\text { estresse psicológico dos } \\
\text { trabalhadores da saúde } \\
\text { causado pela pandemia } \\
\text { COVID-19. }\end{array}$ & $\begin{array}{l}\text { Visto a frequência de sintomas mentais } \\
\text { durante a COVID-19 em profissionais de } \\
\text { saúde é necessário realizar intervenções } \\
\text { em saúde mental para facilitar o seu } \\
\text { enfrentamento. }\end{array}$ \\
\hline $\begin{array}{l}\text { 4. Relato de } \\
\text { Experiência. }\end{array}$ & Equipe Médica & $\begin{array}{l}\text { Desenvolvimento de } \\
\text { intervenções psicológicas } \\
\text { para a equipe médica. }\end{array}$ & $\begin{array}{l}\text { Manter a saúde mental da equipe é } \\
\text { essencial para o controle do impacto das } \\
\text { infecções por COVID-19. }\end{array}$ \\
\hline $\begin{array}{l}\text { 5. Revisão de } \\
\text { Literatura }\end{array}$ & $x$ & $\begin{array}{l}\text { Apresentar intervenções em } \\
\text { saúde física e mental para } \\
\text { proteger os trabalhadores } \\
\text { da saúde no continente } \\
\text { Africano. }\end{array}$ & $\begin{array}{l}\text { A proteção da saúde e do bem-estar } \\
\text { mental dos profissionais da linha de frente } \\
\text { na África impactará a longo prazo na } \\
\text { estabilidade social, econômica e de } \\
\text { segurança no continente. }\end{array}$ \\
\hline
\end{tabular}


Quadro 1. Avaliação final dos estudos incluídos de acordo com a enumeração do Quadro 2 (continuação)

\begin{tabular}{|c|c|c|c|}
\hline MÉTODO & PARTICIPANTES & OBJETIVO & CONCLUSÃO \\
\hline $\begin{array}{l}\text { 6. Relato de } \\
\text { Experiência }\end{array}$ & $\mathrm{x}$ & $\begin{array}{l}\text { Estabelecer as medidas que } \\
\text { os gestores em saúde devem } \\
\text { implementar para proteger a } \\
\text { saúde mental dos } \\
\text { profissionais de saúde. }\end{array}$ & $\begin{array}{l}\text { Os gestores em saúde devem minimizar } \\
\text { os riscos psicológicos da equipe médica } \\
\text { diante da pandemia. }\end{array}$ \\
\hline $\begin{array}{l}\text { 7. Pesquisa } \\
\text { Qualitativa }\end{array}$ & $x$ & $\begin{array}{l}\text { Auxiliar governos, hospitais e } \\
\text { comunidades a } \\
\text { desenvolverem estratégias } \\
\text { em saúde mental a fim de } \\
\text { controlarem o medo e o } \\
\text { pânico da transmissão viral. }\end{array}$ & $\begin{array}{l}\text { O surto da COVID-19 destacou a } \\
\text { fragilidade mental e a necessidade de ter } \\
\text { um plano nacional de intervenção } \\
\text { psicológica. }\end{array}$ \\
\hline $\begin{array}{l}\text { 8. Estudo de } \\
\text { Coorte- } \\
\text { Transversal }\end{array}$ & $\begin{array}{l}246 \\
\text { profissionais da } \\
\text { equipe médica. }\end{array}$ & $\begin{array}{l}\text { Investigar a saúde mental do } \\
\text { corpo clínico da linha de } \\
\text { frente da COVID-19 e } \\
\text { fornecer base teórica para } \\
\text { intervenção psicológica. }\end{array}$ & $\begin{array}{l}\text { Visto a alta incidência de ansiedade e } \\
\text { estresse pós-traumático na equipe } \\
\text { médica, as instituições devem treinar as } \\
\text { habilidades psicológicas dos profissionais. }\end{array}$ \\
\hline $\begin{array}{l}\text { 9. Relato de } \\
\text { Experiência }\end{array}$ & $\begin{array}{l}\text { Profissionais de } \\
\text { saúde }\end{array}$ & $\begin{array}{l}\text { Informar sobre a eficiência e } \\
\text { a qualidade das intervenções } \\
\text { em crises utilizadas por uma } \\
\text { emergência de saúde pública } \\
\text { para os profissionais de } \\
\text { saúde. }\end{array}$ & $\begin{array}{l}\text { As intervenções psicológicas utilizadas } \\
\text { obtiveram bons resultados junto à equipe. }\end{array}$ \\
\hline $\begin{array}{l}\text { 10. Estudo de } \\
\text { Coorte- } \\
\text { Transversal }\end{array}$ & $\begin{array}{l}1.257 \\
\text { profissionais de } \\
\text { saúde }\end{array}$ & $\begin{array}{l}\text { Investigar a saúde mental } \\
\text { dos profissionais de saúde } \\
\text { da China que estão tratando } \\
\text { pacientes com COVID-19. }\end{array}$ & $\begin{array}{l}\text { Dentre os trabalhadores de saúde } \\
\text { chineses, enfermeiras da linha de frente } \\
\text { tem alto risco a prejuízos em sua saúde } \\
\text { mental necessitando de suporte } \\
\text { psicológico ou intervenções. }\end{array}$ \\
\hline $\begin{array}{l}\text { 11. Estudo de } \\
\text { Coorte- } \\
\text { Transversal }\end{array}$ & $\begin{array}{l}2.299 \\
\text { participantes, } \\
\text { sendo } 2.042 \\
\text { funcionários } \\
\text { médicos e } 257 \\
\text { funcionários } \\
\text { administrativos. }\end{array}$ & $\begin{array}{l}\text { Avaliar o estado psicológico } \\
\text { de profissionais que atuam } \\
\text { no contexto hospitalar. }\end{array}$ & $\begin{array}{l}\text { Os profissionais médicos que trabalham } \\
\text { nos departamentos respiratórios, } \\
\text { emergências, UTI e doenças infecciosas } \\
\text { são mais sucessíveis a distúrbios } \\
\text { psicológicos necessitando de estratégias } \\
\text { eficazes para melhorar a saúde mental. }\end{array}$ \\
\hline $\begin{array}{l}\text { 12. Artigo } \\
\text { Original }\end{array}$ & $x$ & $\begin{array}{l}\text { Demonstrar como a } \\
\text { pandemia impacta a saúde } \\
\text { mental dos profissionais de } \\
\text { saúde. }\end{array}$ & $\begin{array}{l}\text { Evidências destacam que cuidados em } \\
\text { saúde mental precisam ser desenvolvidos } \\
\text { com urgência. }\end{array}$ \\
\hline $\begin{array}{l}\text { 13. Revisão } \\
\text { Integrativa }\end{array}$ & $x$ & $\begin{array}{l}\text { Apresentar evidências } \\
\text { cientificas sobre os fatores } \\
\text { associados ao impacto } \\
\text { ocupacional e psicológico } \\
\text { provocado pela pandemia } \\
\text { nos profissionais de saúde. }\end{array}$ & $\begin{array}{l}\text { Este estudo permitiu constatar que } \\
\text { existem fortes evidências disponíveis na } \\
\text { literatura científica sobre os fatores } \\
\text { associados ao impacto ocupacional e } \\
\text { psicológico em profissionais de saúde que } \\
\text { vivenciaram situações de pandemias. } \\
\text { Foram reveladas implicações para o } \\
\text { campo da psicologia, na medida em que } \\
\text { se verificaram os impactos psicológicos } \\
\text { das experiências de profissionais nos } \\
\text { serviços de saúde durante as situações de } \\
\text { pandemias. }\end{array}$ \\
\hline $\begin{array}{l}\text { 14. Artigo } \\
\text { Original }\end{array}$ & $x$ & $\begin{array}{l}\text { Investigar e avaliar a } \\
\text { existência de uma pandemia } \\
\text { de medo com a pandemia da } \\
\text { COVID-19. }\end{array}$ & $\begin{array}{l}\text { É necessário implementar políticas } \\
\text { públicas de saúde mental como estratégia } \\
\text { de resposta a pandemia. Profissionais de } \\
\text { saúde mental devem estar na linha de } \\
\text { frente e desempenhar papel na liderança } \\
\text { desse planejamento. }\end{array}$ \\
\hline
\end{tabular}


Quadro 1. Avaliação final dos estudos incluídos de acordo com a enumeração do Quadro 2(conclusão)

\begin{tabular}{|c|c|c|c|}
\hline MÉTODO & PARTICIPANTES & OBJETIVO & CONCLUSÃO \\
\hline $\begin{array}{l}\text { 15. Revisão } \\
\text { Narrativa }\end{array}$ & $x$ & $\begin{array}{l}\text { Citar os principais } \\
\text { transtornos desenvolvidos, } \\
\text { estratégias e instrumentos } \\
\text { de saúde mental de } \\
\text { pandemias anteriores que } \\
\text { podem ser utilizadas na } \\
\text { promoção de saúde mental } \\
\text { na pandemia atual. }\end{array}$ & $\begin{array}{l}\text { Importância de se investir na promoção da } \\
\text { saúde mental dos profissionais que atuam } \\
\text { na linha de frente, tanto em termos de } \\
\text { pesquisa, quanto de prevenção e } \\
\text { tratamento. }\end{array}$ \\
\hline $\begin{array}{l}\text { 16. Artigo } \\
\text { Original }\end{array}$ & $x$ & $\begin{array}{l}\text { Resumir as primeiras } \\
\text { recomendações para a } \\
\text { redução do estresse e da } \\
\text { carga psicológica em } \\
\text { profissionais de saúde } \\
\text { durante a pandemia da } \\
\text { COVID-19. }\end{array}$ & $\begin{array}{l}\text { Este artigo apresenta diretrizes para } \\
\text { profissionais de saúde e líderes de } \\
\text { equipes na área da saúde que ajudam a } \\
\text { manter a saúde mental durante a } \\
\text { pandemia COVID-19. }\end{array}$ \\
\hline $\begin{array}{l}\text { 17. Revisão } \\
\text { Narrativa }\end{array}$ & $x$ & $\begin{array}{l}\text { Sistematizar conhecimentos } \\
\text { sobre implicações na saúde } \\
\text { mental e intervenções } \\
\text { psicológicas diante da } \\
\text { pandemia do novo } \\
\text { coronavírus. }\end{array}$ & $\begin{array}{l}\text { Em suma, compreende-se que a Psicologia } \\
\text { pode oferecer contribuições importantes } \\
\text { para o enfrentamento das repercussões } \\
\text { da COVID-19, que vem sendo considerada } \\
\text { a maior emergência de saúde pública que } \\
\text { a comunidade internacional enfrenta em } \\
\text { décadas. }\end{array}$ \\
\hline $\begin{array}{l}\text { 18. Estudo } \\
\text { Qualitativo }\end{array}$ & 20 enfermeiras & $\begin{array}{l}\text { Investigar a saúde mental de } \\
\text { enfermeiras que cuidam de } \\
\text { pacientes com CoviD-19. }\end{array}$ & $\begin{array}{l}\text { Durante um surto epidêmico, emoções } \\
\text { positivas e negativas das enfermeiras da } \\
\text { linha de frente se entrelaçaram e } \\
\text { coexistiram. No estágio inicial, as emoções } \\
\text { negativas eram dominantes e as emoções } \\
\text { positivas apareciam gradualmente. Os } \\
\text { estilos de autocuidado e o crescimento } \\
\text { psicológico desempenharam um papel } \\
\text { importante na manutenção da saúde } \\
\text { mental dos enfermeiros. }\end{array}$ \\
\hline $\begin{array}{l}\text { 19. Pesquisa } \\
\text { Clínica }\end{array}$ & $\begin{array}{l}120 \text { equipes } \\
\text { médicas com } \\
\text { idade entre } 25 \text { e } \\
59 \text { anos. }\end{array}$ & $\begin{array}{l}\text { Compreender as mudanças } \\
\text { nos fatores psicológicos e no } \\
\text { estado de sono da equipe } \\
\text { médica da linha de frente da } \\
\text { COVID-19 e fornecer } \\
\text { evidências de intervenções } \\
\text { para aliviar os sintomas. }\end{array}$ & $\begin{array}{l}\text { Existem sintomas psicológicos e de sono } \\
\text { na equipe médica da linha de frente que } \\
\text { participa da luta contra o COVID-19 e eles } \\
\text { afetam uns aos outros. Os hospitais } \\
\text { devem melhorar as medidas de gestão de } \\
\text { emergência, fortalecer o aconselhamento } \\
\text { psicológico para a equipe médica de } \\
\text { primeira linha, fortalecer a intervenção } \\
\text { com exercícios e melhorar a qualidade do } \\
\text { sono e a saúde mental. }\end{array}$ \\
\hline $\begin{array}{l}\text { 20. Artigo } \\
\text { Original }\end{array}$ & $\mathrm{x}$ & $\begin{array}{l}\text { Demonstrar impacto da } \\
\text { pandemia na saúde mental } \\
\text { da população e em especial } \\
\text { nos profissionais de saúde. }\end{array}$ & $\begin{array}{l}\text { Nota-se a importância da intervenção } \\
\text { precoce e de ficar vigilante para sinais de } \\
\text { doença psiquiátrica continua pertinente } \\
\text { neste momento crítico. }\end{array}$ \\
\hline
\end{tabular}

Fonte: Os autores (2020).

\section{Resultados}

A revisão se constituiu através da coleta de 20 publicações acerca das medidas de prevenção, promoção e intervenção aplicadas a saúde mental da classe trabalhadora durante a pandemia da COVID-19. Foram utilizadas, primordialmente, medidas com vista a proteção mental dos profissionais da área da saúde em virtude de sua maior exposição as consequências físicas e psicológicas decorrentes da pandemia, mas podendo também as empregar igualmente em outros setores de trabalho.

No Quadro 2, é possível identificar a origem das pesquisas e consequentemente os países com mais produções que versam sobre as estratégias em saúde mental do trabalhador, destacando-se: Estados Unidos (28,58\%), Reino Unido (19,04\%), Brasil (19,04\%), China (14,30\%), Alemanha (9,52\%), Equador (4,76\%) e Singapura (4,76\%). 
Quadro 2. Distribuição dos artigos que contém medidas de prevenção, promoção ou estratégias de enfrentamento voltadas à saúde mental do trabalhador

\begin{tabular}{|c|c|c|c|c|}
\hline $\mathbf{N}^{\circ}$ & AUTOR (ES) & TíTULO & INDEXADOR & PAís \\
\hline 1 & $\begin{array}{l}\text { Almaguer, A, C., Alvarez, A, K, } \\
\text { G., Santos, E, Z. }\end{array}$ & $\begin{array}{l}\text { Gestión de seguridad psicológica del } \\
\text { personal sanitario en situaciones de } \\
\text { emergencia por COVID-19 en el } \\
\text { contexto hospitalario o de aislamiento }\end{array}$ & Scielo & Equador \\
\hline 2 & $\begin{array}{l}\text { Blake, H., Bermingham, F., } \\
\text { Johnson, G., \& Tabner, A. }\end{array}$ & $\begin{array}{l}\text { Mitigating the Psychological Impact of } \\
\text { COVID-19 on Healthcare Workers: A } \\
\text { Digital Learning Package }\end{array}$ & Pubmed & Reino Unido \\
\hline 3 & $\begin{array}{l}\text { Bohlken, J., Schömig, F., Lemke, } \\
\text { M., Pumberger, M., \& Riedel- } \\
\text { Heller, S. }\end{array}$ & $\begin{array}{l}\text { COVID-19 Pandemic: Stress Experience } \\
\text { of Healthcare Workers - A Short } \\
\text { Current Review }\end{array}$ & Pubmed & Alemanha \\
\hline 4 & $\begin{array}{l}\text { Chen, Q., Liang, M., Li, Y., Guo, } \\
\text { J., Fei, D., \& Wang, L. et al. }\end{array}$ & $\begin{array}{l}\text { Mental health care for medical staff in } \\
\text { China during the COVID-19 outbreak }\end{array}$ & Pubmed & China \\
\hline 5 & $\begin{array}{l}\text { Chersich, M., Gray, G., Fairlie, } \\
\text { L., Eichbaum, Q., Mayhew, S., \& } \\
\text { Allwood, B. et al. }\end{array}$ & $\begin{array}{l}\text { COVID-19 in Africa: care and } \\
\text { protection for frontline healthcare } \\
\text { workers }\end{array}$ & Pubmed & Reino Unido \\
\hline 6 & $\begin{array}{l}\text { Greenberg, N., Docherty, M., } \\
\text { Gnanapragasam, S., \& Wessely, } \\
\text { S. }\end{array}$ & $\begin{array}{l}\text { Managing mental health challenges } \\
\text { faced by healthcare workers during } \\
\text { covid-19 pandemic. }\end{array}$ & Pubmed & Reino Unido \\
\hline 7 & Ho, C. S., Chee, C. Y., \& Ho, R. C. & $\begin{array}{l}\text { Mental Health Strategies to Combat } \\
\text { the Psychological Impact of COVID-19 } \\
\text { Beyond Paranoia and Panic }\end{array}$ & Pubmed & Singapura \\
\hline 8 & $\begin{array}{l}\text { Huang, J. Z., Han, M. F., Luo, T. } \\
\text { D., Ren, A. K., \& Zhou, X. P. }\end{array}$ & $\begin{array}{l}\text { Mental Health Survey of Medical Staff } \\
\text { in a Tertiary Infectious Disease } \\
\text { Hospital for COVID-19 }\end{array}$ & Pubmed & China \\
\hline 9 & $\begin{array}{l}\text { Kang, L., Li, Y., Hu, S., Chen, M., } \\
\text { Yang, C.,; Yang, B,X., Wang, Y., } \\
\text { Hu, J., Lai, J., Ma, X., . }\end{array}$ & $\begin{array}{l}\text { The mental health of medical workers } \\
\text { in Wuhan, China dealing with the } 2019 \\
\text { novel coronavirus }\end{array}$ & Pubmed & China \\
\hline 10 & $\begin{array}{l}\text { Lai, J., Ma, S., Wang, Y., Cai, Z., } \\
\text { Hu, J., \& Wei, N. et al. }\end{array}$ & $\begin{array}{l}\text { Factors Associated With Mental Health } \\
\text { Outcomes Among Health Care } \\
\text { Workers Exposed to Coronavirus } \\
\text { Disease } 2019\end{array}$ & Pubmed & EUA \\
\hline 11 & Lu, W., Wang, H., Lin, Y., \& Li, L. & $\begin{array}{l}\text { Psychological Status of Medical } \\
\text { Workforce During the COVID-19 } \\
\text { Pandemic: A Cross-Sectional Study }\end{array}$ & Pubmed & EUA \\
\hline 12 & $\begin{array}{l}\text { Neto, M., Almeida, H. G., } \\
\text { Esmeraldo, J. D., Nobre, C. B., } \\
\text { Pinheiro, W. R., de Oliveira, C., } \\
\text { Sousa, I., Lima, O., Lima, N., } \\
\text { Moreira, M. M., Lima, C., Júnior, } \\
\text { J. G., \& da Silva, C. }\end{array}$ & $\begin{array}{l}\text { When health professionals look death } \\
\text { in the eye: the mental health of } \\
\text { professionals who deal daily with the } \\
2019 \text { coronavirus outbreak }\end{array}$ & Pubmed & EUA \\
\hline 13 & $\begin{array}{l}\text { Oliveira, W., Oliveira-Cardoso, } \\
\text { É., Silva, J., \& Santos, M. }\end{array}$ & $\begin{array}{l}\text { Impactos psicológicos e ocupacionais } \\
\text { das sucessivas ondas } \\
\text { recentes de pandemias em } \\
\text { profissionais da saúde: revisão } \\
\text { integrativa e lições aprendidas }\end{array}$ & Scielo & Brasil \\
\hline 14 & $\begin{array}{l}\text { Ornell, Felipe, Schuch, } \\
\text { Jaqueline B., Sordi, Anne O., \& } \\
\text { Kessler, Felix Henrique Paim. }\end{array}$ & $\begin{array}{l}\text { Pandemic fear" and COVID-19: mental } \\
\text { health burden and strategies }\end{array}$ & Scielo & Brasil \\
\hline 15 & $\begin{array}{l}\text { Ornell, F., Halpern, S, C., } \\
\text { Kessler, F, H, P., \& Narvaez, J, C. }\end{array}$ & $\begin{array}{l}\text { The impact of the COVID-19 pandemic } \\
\text { on the mental health of healthcare } \\
\text { professionals }\end{array}$ & Scielo & Brasil \\
\hline 16 & $\begin{array}{l}\text { Petzold, M., Plag, J., \& Ströhle, } \\
\text { A. }\end{array}$ & $\begin{array}{l}\text { Dealing With Psychological Distress by } \\
\text { Healthcare Professionals During the } \\
\text { COVID-19 Pandemia [Umgang mit } \\
\text { psychischer Belastung bei } \\
\text { Gesundheitsfachkräften im Rahmen } \\
\text { der Covid-19-Pandemie] }\end{array}$ & Pubmed & Alemanha \\
\hline 17 & $\begin{array}{l}\text { Schmidt, B., Crepaldi, M, A., } \\
\text { Bolze, S, D, A., Neiva-Silva, L., } \\
\text { Demenech, L, M. }\end{array}$ & $\begin{array}{l}\text { Saúde mental e intervenções } \\
\text { psicológicas diante da pandemia do } \\
\text { novo coronavírus (COVID-19) }\end{array}$ & Scielo & Brasil \\
\hline 18 & $\begin{array}{l}\text { Sun, N., Wei, L., Shi, S., Jiao, D., } \\
\text { Song, R., \& Ma, L. et al. }\end{array}$ & $\begin{array}{l}\text { A qualitative study on the } \\
\text { psychological experience of caregivers } \\
\text { of COVID-19 patients }\end{array}$ & Pubmed & EUA \\
\hline 19 & Wu, K., \& Wei, X. & $\begin{array}{l}\text { Analysis of Psychological and Sleep } \\
\text { Status and Exercise Rehabilitation of } \\
\text { Front-Line Clinical Staff in the Fight } \\
\text { Against COVID-19 in China }\end{array}$ & Pubmed & EUA \\
\hline 20 & $\begin{array}{l}\text { Yahya, AS., Khawaja, S., } \\
\text { Chukwuma, J. }\end{array}$ & The Impact of COVID-19 in Psychiatry & Pubmed & EUA \\
\hline
\end{tabular}

Fonte: Os autores (2020). 
No que concerne ao enfoque das publicações, foram identificadas medidas de caráter preventivo, bem como de promoção à saúde mental dos trabalhadores, tanto para serem executadas pelos profissionais de saúde mental por deliberação da organização em que se trabalha quanto por ação governamental. Além disso, reconheceuse instrumentos psicológicos como o uso de testes, escalas e questionários para rastreamento de sintomas que apontam para a manifestação de sofrimento psíquico ou até mesmo para possíveis casos de Transtornos Psicopatológicos. Enfim, observou-se a utilização de estratégias, intervenções e técnicas psicológicas como ferramentas para a sustentação das medidas de prevenção e promoção à saúde mental. Sendo assim, com a finalidade de demonstrar minuciosamente os dados encontrados, estes foram exemplificados nos Quadros 3, 4, 5 e 6, levando em consideração a ordem de enumeração dos artigos apresentados no Quadro 2. Logo, cada dado possui, ao seu lado, a numeração dos artigos correspondentes.

As medidas de prevenção à saúde mental mais recorrentes entre os trabalhos pesquisados (dispostos no Quadro 3 ) são: os turnos rotativos de trabalho $(28,6 \%)$, períodos de descansos regulares $(23,8 \%)$, realização de treinamento de pessoal (23,8\%), identificação precoce dos sintomas (19\%), comunicação diretiva e clara (19\%), divulgação dos serviços de apoio e medidas psicossociais (14,3\%) e identificação das demandas dos profissionais através do diálogo presencial ou virtual, adaptando as orientações gerais e especificidades do local (14,3\%). Ao observar os responsáveis pela execução destas medidas, é possível notar que das 7 citadas, 6 são executadas pelas organizações, o que evidencia a importância das corporações no cuidado a saúde mental dos seus funcionários e, consequentemente, contribuindo para a saúde da população em geral. Tais medidas, mais encontradas em estudos oriundos de países como Equador, Singapura e Brasil, objetivam reduzir os níveis de estresse entre as equipes de saúde, identificar possíveis demandas e dar encaminhamento dentro das possibilidades.

Quadro 3. Medidas de prevenção a saúde mental de acordo a enumeração do Quadro 2

\begin{tabular}{|c|c|c|c|c|}
\hline ITEM & $\begin{array}{l}\text { MEDIDAS DE PREVENÇÃO A } \\
\text { SAÚDE MENTAL }\end{array}$ & ARTIGOS & $\begin{array}{l}\text { RESPONSÁVEIS PELA } \\
\text { EXECUÇÃO DAS } \\
\text { MEDIDAS }\end{array}$ & $\begin{array}{l}\text { QTD DE ARTIGOS } \\
\text { QUE PROPÕEM A } \\
\text { MEDIDA }\end{array}$ \\
\hline 1 & Turnos rotativos de trabalho & $\begin{array}{l}\text { [1]; [2]; [3]; [7]; } \\
{[9] ;[16] .}\end{array}$ & Organização. & 6 \\
\hline 2 & $\begin{array}{l}\text { Fornecer Períodos de descansos } \\
\text { regulares }\end{array}$ & $\begin{array}{l}{[1] ;[7] ;} \\
{[16] ;[17] .}\end{array}$ & Organização. & 5 \\
\hline 3 & $\begin{array}{l}\text { Realização de treinamento de } \\
\text { pessoal }\end{array}$ & $\begin{array}{l}\text { [1]; [7]; [9]; [14]; } \\
\text { [15]. }\end{array}$ & Organização. & 5 \\
\hline 4 & $\begin{array}{l}\text { Identificação precoce dos } \\
\text { sintomas }\end{array}$ & [7]; [10]; [14]; [15]. & $\begin{array}{l}\text { Profissionais de saúde } \\
\text { mental. }\end{array}$ & 4 \\
\hline 5 & Comunicação diretiva e clara & [2]; [7]; [16]. & Organização. & 4 \\
\hline 6 & $\begin{array}{l}\text { Divulgação dos serviços de } \\
\text { apoio e medidas psicossociais }\end{array}$ & {$[15] ;[16]$.} & Organização. & 3 \\
\hline 7 & $\begin{array}{l}\text { Identificar as demandas dos } \\
\text { profissionais através do diálogo } \\
\text { adaptando as orientações gerais } \\
\text { as especificidades do local. }\end{array}$ & [1]; [4]; [7]. & Organização. & 3 \\
\hline 8 & $\begin{array}{l}\text { Identificação de grupo de risco } \\
\text { psicológico. }\end{array}$ & [10]; [15]. & $\begin{array}{l}\text { Profissionais de saúde } \\
\text { mental. }\end{array}$ & 2 \\
\hline 9 & $\begin{array}{l}\text { Intervenções psicológicas e } \\
\text { psiquiátricas precoce. }\end{array}$ & [15]; [18] & $\begin{array}{l}\text { Profissionais de saúde } \\
\text { mental. }\end{array}$ & 2 \\
\hline 10 & $\begin{array}{l}\text { Estabelecer um plano preventivo } \\
\text { de contingência para lidar com } \\
\text { problemas mais sérios sintomas } \\
\text { psiquiátricos }\end{array}$ & [14]; [15]. & $\begin{array}{l}\text { Profissionais de saúde } \\
\text { mental. }\end{array}$ & 2 \\
\hline 11 & $\begin{array}{l}\text { Reconhecimento dos esforços } \\
\text { colocados no trabalho }\end{array}$ & {$[1] ;[16]$.} & Organização. & 2 \\
\hline 12 & $\begin{array}{l}\text { Definir ferramentas para } \\
\text { monitorar a saúde mental. }\end{array}$ & {$[15]$} & $\begin{array}{l}\text { Profissionais de saúde } \\
\text { mental. }\end{array}$ & 1 \\
\hline 13 & $\begin{array}{l}\text { Identificar profissionais com } \\
\text { condições psiquiátricas } \\
\text { anteriores (depressão, burnout, } \\
\text { transtornos de ansiedade, } \\
\text { transtorno bipolar, trauma...) }\end{array}$ & [15] & $\begin{array}{l}\text { Profissionais de saúde } \\
\text { mental. }\end{array}$ & 1 \\
\hline
\end{tabular}


Em relação às medidas de promoção a saúde mental, mais encontradas em estudos do Equador, Reino Unido, Brasil, Alemanha e Singapura, a atuação dos profissionais da área é reconhecida como um fator importante para o cuidado e tratamento daqueles que estão sofrendo os impactos da pandemia. Entre as medidas de promoção mais citadas estão: Fornecer apoio psicológico aos profissionais de saúde para facilitar a expressão emocional (33,3\%); Fornecer ajuda na identificação de necessidades, preocupações mais recorrentes e nas estratégias de desenvolvimento (28,6\%); Desenvolver materiais psicoeducativos e informativos que promovam cuidados de saúde mental (23,8\%); Realizar planos de tratamento psíquico e fornecer aconselhamento psicológico (23,8\%); Gerenciamento de crises (23,8\%); Proporcionar um clima organizacional saudável; Realizar intervenções psicológicas clínicas (19\%) e Padronizar medicamentos psicotrópicos e disponibilizá-los (19\%).

Observando o Quadro 4, também é possível identificar que as responsabilidades se dividem entre profissionais de saúde mental, ações governamentais e organizações, sendo o profissional da saúde mental responsável por 6 das 8 medidas mais utilizadas.

Quadro 4. Medidas de promoção a saúde mental de acordo a enumeração do Quadro 2 (continua)

\begin{tabular}{|c|c|c|c|c|}
\hline ITEM & $\begin{array}{l}\text { MEDIDAS DE PROMOÇÃO A } \\
\text { SAÚDE MENTAL }\end{array}$ & ARTIGOS & $\begin{array}{l}\text { RESPONSÁVEIS PELA } \\
\text { EXECUÇÃO DAS } \\
\text { MEDIDAS }\end{array}$ & $\begin{array}{l}\text { QTD DE } \\
\text { ARTIGOS QUE } \\
\text { PROPÕEM A } \\
\text { MEDIDA }\end{array}$ \\
\hline 1 & $\begin{array}{l}\text { Fornecer apoio psicológico aos } \\
\text { profissionais de saúde para } \\
\text { facilitar a expressão emocional }\end{array}$ & $\begin{array}{l}\text { [2]; [8]; [13]; [15]; [16]; } \\
{[17] ;[19] .}\end{array}$ & $\begin{array}{l}\text { Profissionais de } \\
\text { saúde mental. }\end{array}$ & 7 \\
\hline 2 & $\begin{array}{l}\text { Fornecer ajuda na identificação } \\
\text { de necessidades, preocupações } \\
\text { recorrentes e nas estratégias de } \\
\text { desenvolvimento }\end{array}$ & [1]; [2]; [3]; [7]; [9]; [16]. & $\begin{array}{l}\text { Profissionais de } \\
\text { saúde mental. }\end{array}$ & 6 \\
\hline 3 & $\begin{array}{l}\text { Desenvolver materiais } \\
\text { psicoeducacionais e informativos } \\
\text { que promovam cuidados de } \\
\text { saúde mental. }\end{array}$ & [2]; [3]; [9]; [14]; [15] & $\begin{array}{l}\text { Profissionais de } \\
\text { saúde mental + } \\
\text { Governo. }\end{array}$ & 5 \\
\hline 4 & $\begin{array}{l}\text { Realizar planos de tratamento } \\
\text { psíquico e fornecer } \\
\text { aconselhamento psicológico }\end{array}$ & [5]; [7]; [12]; [15]; [20]. & $\begin{array}{l}\text { Profissionais de } \\
\text { saúde mental. }\end{array}$ & 5 \\
\hline 5 & Gerenciamento de crises. & [1]; [7]; [16]; [17]. & $\begin{array}{l}\text { Profissionais de } \\
\text { saúde mental. }\end{array}$ & 5 \\
\hline 6 & $\begin{array}{l}\text { Proporcionar um clima } \\
\text { organizacional saudável. }\end{array}$ & [1]; [7]; [9]; [14]; [15]. & Organizações. & 5 \\
\hline 7 & $\begin{array}{l}\text { Realizar intervenções } \\
\text { psicológicas clínicas }\end{array}$ & [3]; [9]; [15]. & $\begin{array}{l}\text { Profissionais de } \\
\text { saúde mental. }\end{array}$ & 4 \\
\hline 8 & $\begin{array}{l}\text { Padronizar medicamentos } \\
\text { psicotrópicos e disponibilizá-los }\end{array}$ & {$[2] ;[7] ;[16]$} & Governos & 4 \\
\hline 9 & $\begin{array}{l}\text { Fornecer assistência psicológica } \\
\text { remota e rede de suporte. }\end{array}$ & [1]; [4]; [7] & $\begin{array}{l}\text { Profissionais de } \\
\text { saúde mental. }\end{array}$ & 3 \\
\hline 10 & $\begin{array}{l}\text { Desenvolver ações voltadas à } \\
\text { atenção em saúde mental após o } \\
\text { término da pandemia. }\end{array}$ & {$[6] ;[15]$} & $\begin{array}{l}\text { Profissionais de } \\
\text { saúde mental. }\end{array}$ & 2 \\
\hline
\end{tabular}


Quadro 4. Medidas de promoção a saúde mental de acordo a enumeração do Quadro 2 (conclusão)

\begin{tabular}{|c|c|c|c|c|}
\hline ITEM & $\begin{array}{l}\text { MEDIDAS DE PROMOÇÃO A } \\
\text { SAÚDE MENTAL }\end{array}$ & ARTIGOS & $\begin{array}{l}\text { RESPONSÁVEIS PELA } \\
\text { EXECUÇÃO DAS } \\
\text { MEDIDAS }\end{array}$ & $\begin{array}{l}\text { QTD DE } \\
\text { ARTIGOS QUE } \\
\text { PROPÕEM A } \\
\text { MEDIDA }\end{array}$ \\
\hline 11 & $\begin{array}{l}\text { Implementar ações de atenção } \\
\text { em saúde mental. }\end{array}$ & [1]; [15]. & $\begin{array}{l}\text { Profissionais de } \\
\text { saúde mental. }\end{array}$ & 2 \\
\hline 12 & $\begin{array}{l}\text { Fornecer atendimento de } \\
\text { emergência e primeiros socorros } \\
\text { psicológicos }\end{array}$ & [7]; [15]. & $\begin{array}{l}\text { Profissionais de } \\
\text { saúde mental. }\end{array}$ & 2 \\
\hline 13 & $\begin{array}{l}\text { Grupos terapêuticos de suporte } \\
\text { mental }\end{array}$ & [1]; [16] & $\begin{array}{l}\text { Profissionais de } \\
\text { saúde mental. }\end{array}$ & 2 \\
\hline
\end{tabular}

Fonte: Os autores (2020).

Dentre as intervenções e estratégias apresentadas no Quadro 5, nota-se que as estratégias de autocuidado, fortalecimento das redes de apoio e a prática dos exercícios físicos são as mais frequentes, podendo ser encontradas nos estudos publicados em países como Equador, Alemanha, Brasil e Reino Unido, e mais aplicadas em profissionais da saúde.

Quadro 5. Intervenções e estratégias psicológicas enumeradas de acordo com o Quadro 2

\begin{tabular}{|c|c|c|c|}
\hline ITEM & INTERVENÇÕES E ESTRATÉGIAS PSICOLÓGICAS & ARTIGOS & $\begin{array}{l}\text { QTD DE ARTIGOS } \\
\text { QUE CITAM DADA } \\
\text { INTERVENÇÃO }\end{array}$ \\
\hline 1 & Estratégias de autocuidado & {$[1] ;[16] ;[17] ;[19]$.} & 5 \\
\hline 2 & $\begin{array}{l}\text { Fortalecimento das redes de apoio por meio de } \\
\text { telefonemas, mensagens de textos e áudios }\end{array}$ & [1]; [2]; [9]; [17]; [19]. & 5 \\
\hline 3 & $\begin{array}{l}\text { Exercícios físicos e dieta (ioga, tai chi, qigong) e } \\
\text { nutrição }\end{array}$ & {$[1] ;[15] ;[19]$.} & 4 \\
\hline 4 & Estratégias de gerenciamento de estresse & [15]; [17]; [19]. & 3 \\
\hline 5 & Kits Primeiros socorros psicológicos & {$[1] ;[15] ;[16]$.} & 3 \\
\hline 6 & $\begin{array}{l}\text { Tratamento psiquiátrico e farmacológico para casos } \\
\text { graves }\end{array}$ & [12]; [14]; [15]. & 3 \\
\hline 7 & Suporte de pares & {$[15] ;[16] ;[20]$} & 3 \\
\hline 8 & Intervenções de estresse pós-traumático & [15]; [19]. & 2 \\
\hline 9 & Aconselhamento individual & {$[3] ;[15]$} & 2 \\
\hline 10 & Avaliações de saúde mental & [15]; [19]. & 2 \\
\hline 11 & $\begin{array}{l}\text { Visitas psicológicas as áreas de descanso para escuta } \\
\text { dos profissionais }\end{array}$ & {$[17] ;[19]$.} & 2 \\
\hline 12 & Técnicas de atenção plena & [15] & 1 \\
\hline 13 & Meditação guiada & [15] & 1 \\
\hline 14 & Meditação musical & {$[18]$} & 1 \\
\hline 15 & Intervenções em psicoeducação & [15] & 1 \\
\hline 16 & Protocolos de prevenção de Burnout & [15] & 1 \\
\hline 17 & Grupos terapêuticos & [15] & 1 \\
\hline 18 & Estratégias de Psicologia Positiva & [15] & 1 \\
\hline 19 & Intervenções breves de ansiedade e depressão & {$[15]$} & 1 \\
\hline 20 & Protocolos de prevenção do suicídio & [15] & 1 \\
\hline 21 & Técnicas de mindfulness e meditação & {$[15]$} & 1 \\
\hline
\end{tabular}

Fonte: Os autores (2020).

No Quadro 6 é possível perceber que os instrumentos mais utilizados são os psicométricos com foco na avaliação do estado de ansiedade, sendo citadas 03 ferramentas diferentes para análise deste construto. $\mathrm{O}$ instrumento para avaliação no nível de depressão foi o segundo mais citado dentre os estudos. 
Quadro 6. Instrumentos psicológicos enumerados de acordo com o Quadro 2

\begin{tabular}{|c|c|c|c|}
\hline ITEM & INTRUMENTOS & ARTIGOS & $\begin{array}{l}\text { QTD DE ARTIGOS QUE } \\
\text { CITAM DETERMINADO } \\
\text { INSTRUMENTO }\end{array}$ \\
\hline 1 & Transtorno de Ansiedade Generalizada (GAD-7) & {$[3] ;[10]$.} & 2 \\
\hline 2 & Escala de Ansiedade de Hamilton (HAMA) & [11]; [15]. & 2 \\
\hline 3 & Escala de Depressão de Hamilton (HAMD)- & {$[11] ;[15]$} & 2 \\
\hline 4 & Escala de Ansiedade e Autoavaliação (SAS) & [12]; [15]. & 2 \\
\hline 5 & Escala de Impacto de Eventos (IES-R) & [3] & 1 \\
\hline 6 & Health Questionnaire-9 (PHQ-9) & {$[3]$} & 1 \\
\hline 7 & $\begin{array}{l}\text { Burnout: Inventário de Burnout Maslach - Serviços } \\
\text { Humanos }\end{array}$ & {$[15]$} & 1 \\
\hline 8 & Pesquisa (MBI-HSS) & [15] & 1 \\
\hline 9 & Estresse no trabalho: Job Stress Scale (JSS) & [15] & 1 \\
\hline 10 & $\begin{array}{l}\text { Rastreando transtornos mentais não psicóticos: } \\
\text { auto-relato Questionário (SRQ-20) }\end{array}$ & [15] & 1 \\
\hline 11 & $\begin{array}{l}\text { Rastreando transtornos mentais: sintoma de vários } \\
\text { níveis do DSM-5 Escala }\end{array}$ & {$[15]$} & 1 \\
\hline 12 & Álcool e drogas: álcool, tabagismo e substâncias & {$[15]$} & 1 \\
\hline 13 & Teste de triagem de envolvimento (ASSIST) / OMS & [15] & 1 \\
\hline 14 & $\begin{array}{l}\text { Qualidade de vida: Qualidade de Vida da } \\
\text { Organização Mundial da Saúde }\end{array}$ & {$[15]$} & 1 \\
\hline 15 & Versão curta (WHOQOL-bref) & {$[15]$} & 1 \\
\hline 16 & Operação: Breve Escala de Operação (FAST) & [15] & 1 \\
\hline 17 & Resiliência: Escala de pilares de resiliência (EPR) & [15] & 1 \\
\hline 18 & $\begin{array}{l}\text { Escala de Auto-classificação do Transtorno de } \\
\text { Estresse Pós-Traumático (PTSD-SS). }\end{array}$ & {$[8]$} & 1 \\
\hline 19 & Índice de Gravidade de Insônia & {$[10]$} & 1 \\
\hline
\end{tabular}

Fonte: Os autores (2020).

\section{Discussão}

O alastramento da COVID-19 em escala global gerou impactos em todo o mundo, saturando os sistemas de saúde e trazendo modificações sem precedentes no campo do trabalho. Em razão disso, notam-se os possíveis efeitos na saúde mental do trabalhador, em especial, aqueles que atuam na linha de frente ao combate da pandemia, enfrentando pressões diárias e os estigmas da profissão. Contudo, os prejuízos psicológicos para esta população são capazes de transcender o momento atual, podendo gerar traumas com duração de médio e longo prazo, como sinaliza Ornell et al. (2020), ao se basear em dados de surtos respiratórios anteriores como o SARS de 2003 e o MERS de 2015 e como estes proporcionaram prejuízos psíquicos aos profissionais de saúde mesmo após suas saídas do ambiente de trabalho.

Atualmente, entre os profissionais de saúde, observa-se um aumento significativo de transtornos depressivos, ansiosos, estresse pós-traumático, estresse agudo e síndrome de Burnout. Este sofrimento psíquico, em sua maioria, é causado pelas rotinas extenuantes, cenário de incerteza, risco de contaminação, medo de transmissão à família, entre outros fatores que geram adoecimento (Ho et al., 2020; Huang, J. et al., 2020; Oliveira et al., 2020; Ornell et al., 2020; Sun et al., 2020; Wu \& Wei, 2020). Diante desse quadro, para rastreamento dos sintomas e identificação dos transtornos, parte dos estudos coletados utilizaram instrumentos psicológicos, destacando-se aqueles que avaliavam os níveis de ansiedade e depressão. 
Em um estudo de revisão feito por Bohlken et al. (2020) sobre o estresse psicológico dos trabalhadores da área de saúde causado pela pandemia vigente, em uma amostra variável entre 37 e 1.257 participantes, também foram evidenciados altos índices de impactos psicológicos, no qual destacavam-se sintomas de ansiedade, depressão e estresse. Igualmente, Lai et al. (2020), em um estudo transversal com 1.257 profissionais também da área saúde, destacou a preponderância de sintomas de depressão, ansiedade, insônia e sofrimento. Sendo assim, sugere-se que este é um dos principais sintomas apresentados pelos trabalhadores de saúde, o que por sua vez, destaca o uso e eficácia dos instrumentos: Transtorno de Ansiedade Generalizada (GAD7), Escala de Ansiedade de Hamilton (HAMA), Escala de Depressão de Hamilton (HAMD) e a Escala de Ansiedade e Autoavaliação (SAS), dado que a própria amostra desse e de outros estudos com resultados semelhantes utilizam dos instrumentos citados (Lu et al., 2020; Ornell et al., 2020; Neto et al., 2020).

Dentro deste contexto, além da identificação de sinais e sintomas prontamente associados a transtornos psiquiátricos, é fundamental pensar em estratégias de prevenção e promoção a saúde mental dos profissionais que atuam no combate a COVID-19, haja vista que, estando na linha de frente, eles são essenciais para manter a funcionalidade do sistema de saúde (Petzold et al., 2020) e, consequentemente, combater a pandemia.

As medidas de prevenção à saúde mental ilustradas no Quadro 3 destacam o papel ativo das organizações em proporcionar maiores possibilidades de prevenção aos prejuízos possíveis para a saúde mental, visto que tais medidas objetivam reduzir os níveis de estresse entre as equipes de saúde, identificar possíveis demandas e dar encaminhamento dentro das possibilidades. Isto, por sua vez, evidencia a importância das corporações no cuidado a saúde mental dos seus funcionários e, desta forma, contribuindo para a saúde da população em geral.

Para Almaguer et al., (2020), ao pensar maneiras de prevenir prejuízos a saúde mental do trabalhador é necessário estabelecer um nível de organização claro, diretivo e se possível divido em fases, em que tornase possível pensar os impactos ocasionados pelo dia a dia do trabalho. De acordo com o autor, os turnos rotativos de trabalho podem ajudar a prevenir esses impactos a saúde mental, dado que, como demonstra Bohlken et al. (2020) em um outro estudo, o nível de impacto e prejuízo a saúde mental do trabalhador pode variar de acordo com o nível de exposição deste a possibilidade de infecção com o vírus.

Ainda sobre os turnos rotativos como estratégia de prevenção, Blake et al. (2020) desenvolveram e avaliaram um pacote de aprendizado digital usando a metodologia Agile com o intuito de minimizar os impactos a saúde mental do trabalhador. Dentre as estratégias elencadas pelos autores de acordo com a opinião de especialistas que ajudaram com o pacote, os turnos rotativos de trabalho aparecem como uma estratégia possivelmente eficaz, sobretudo por reduzir o nível de exposição e sobrecarga dos trabalhadores.

É valido destacar que no início da pandemia os hospitais na China já utilizavam dessa estratégia e de certa maneira evidenciava um menor índice de prejuízo à saúde mental dos trabalhadores (Kang et al., 2020).

Embora os turnos rotativos de trabalho se destaquem como a principal medida preventiva, outras medidas como: período de descansos regulares, realização de treinamento pessoal, identificação precoce dos sintomas e comunicação diretiva e clara, também são demasiadamente importantes.

Segundo Almaguer et al. (2020) e Blake et al. (202), o fornecimento de período de descansos regulares diminui possíveis impactos a saúde do trabalhador, por vez, igualmente a estratégia de turnos rotativos de trabalho. Em concordância com isso, Ho et al. (2020) ressaltam a evidente eficácia que os descansos proporcionam para a prevenção desses impactos e melhores resultados psicológicos.

A realização de treinamento pessoal e identificação precoce dos sintomas são eficientes na medida que são bem realizadas. De acordo com Ornell et al. (2020), ao se referir a treinamento pessoal, tem-se em mente um treinamento organizado, como, por exemplo, um treinamento com base em protocolos de gerenciamento de estresse, trauma, depressão e comportamento de risco. Esses treinamentos, portanto, podem vir a ajudar na identificação precoce dos sintomas. Sendo assim, essas duas estratégias se estruturam como uma ferramenta essencial a ser utilizada pelas organizações. 
Em relação as medidas de promoção a saúde mental, a atuação dos profissionais da área é reconhecida como um fator importante para o cuidado e tratamento daqueles que estão sofrendo os impactos da pandemia. Dentre essas medidas de promoção, segundo Blake (2020) e Petzold et al. (2020), fornecer apoio psicológico aos profissionais de saúde, visando facilitar a expressão emocional, proporciona um aumento significativo do bem-estar psicológico dos trabalhadores expostos a COVID-19. Além disso, ainda com base em Petzold et al. (2020), esse apoio emocional pode, consequentemente, diminuir os casos de alto grau de prejuízo à saúde mental (depressão, ansiedade e estresse) que são tão frequentes na população trabalhadora atualmente. Portanto, torna-se possível concluir e acrescentar que a expressão emocional é uma estratégia que proporciona a simbolização do processo de vivência da pandemia.

Ainda visando a promoção da saúde mental dos trabalhadores, o desenvolvimento de materiais psicoeducativos e informativos que promovam cuidados à saúde mental também se tornam demasiadamente eficazes e importantes (Blake et al., 2020; Bohlken et al., 2020), visto que uma boa parte dos trabalhadores da área de saúde possuem um baixo nível de instrução a respeito de questões psicológicas, sobretudo no Brasil (Schmitd et al., 2020).

Dentre as medidas, outras ainda se destacam, como é o caso da realização de planos de tratamento mental e o fornecimento de aconselhamento psicológicos com base nas demandas mais frequentes, bem como as individuais (Chersich, 2020; Ho et al., 2020; Yahya et al., 2020), assim como o gerenciamento de crises (Almaguer et al., 2020; Petzold et al., 2020).

Diferente das medidas de prevenção que concentravam grande parte das responsabilidades nas organizações, as medidas de promoção se dividem entre profissionais de saúde mental, ações governamentais e organizações, sendo o profissional da saúde mental o principal agente na execução dessas medidas, logo, o mais importante. Esses dados apontam para a importância daqueles que trabalham com saúde mental se instrumentalizarem para as demandas atuais e as que possam vir a surgir após a crise, pois já existe uma grande necessidade de atenção aos profissionais de saúde, que deve se refletir em outros setores de trabalho com o decorrer do tempo. Assim, cabe aos profissionais de psicologia atuarem no desenvolvimento de ferramentas de promoção e prevenção a saúde psicológica mediante suporte, orientações e diretrizes acerca do gerenciamento das situações vivenciadas (Schmidt et al., 2020).

No tocante à forma como esses profissionais podem manejar os impactos a sua saúde com o uso de estratégias de enfrentamento, os estudos destacam a maior eficácia do autocuidado e fortalecimento da rede de apoio tanto familiar tanto quanto entre os próprios profissionais. A importância do fortalecimento da rede de apoio encontra respaldo no alto índice de casos de depressão como já mencionado, assim como relatos de solidão vividos pelos profissionais na linha de frente (Almaguer et al. 2020; Wu \& Wei, 2020)

Além disso, a prática de atividade física e uma dieta regular também aparecem como eficazes para o enfrentamento da atual situação pandêmica (Wu \& Wei, 2020). De acordo com os autores, o exercício físico bem adequado e o nível de intensidade do exercício podem ajudar a melhorar significativamente a qualidade do sono e a saúde mental e física.

No entanto, conforme Sun et al. (2020) salienta, cada sujeito desenvolve os seus próprios métodos de enfretamento e através deles podem promover ajustes psicológicos tanto em escala emocional como cognitiva para suportarem o cenário adverso de trabalho. Sendo assim, embora grande parte das estratégias aqui elucidadas apontem para a execução por parte das organizações ou dos profissionais de saúde mental, o próprio sujeito também é um agente ativo diante das incertezas e situações adversas da pandemia, ressaltando então, a capacidade de cada indivíduo em desenvolver suas próprias estratégias ou utilizar das estratégias aqui encontradas da sua maneira, validando a teoria de Lazarus e Folkman (1984) acercado do coping.

Assim, por meio desta revisão, observou-se a existência de poucos estudos científicos que abordem modelos de intervenção focados na saúde mental de profissionais envolvidos na assistência aos pacientes com a COVID-19, assim como de outros setores do mundo trabalho. Dos 20 artigos encontrados, 19 apresentam como foco os profissionais de saúde, enquanto 2 , além de abordarem a saúde mental dos profissionais, tocam na saúde da população em 
geral - embora esses dois estudos mencionem a saúde mental da população trabalhadora em conjunto com a população geral, foram consideradas somente as propostas direcionados ao público trabalhador e ao campo organizacional. Posto isto, uma limitação também observada, foi a falta de clareza sobre a profissão dos trabalhadores pesquisados. Comumente são utilizados termos genéricos como "Equipe Médica", promovendo uma barreira na visualização de quais trabalhadores foram pesquisados especificamente, assim, poucos são os estudos que nos permitem analisar se alguma categoria é mais afetada do que outra.

Além disso, foi possível observar que dos 20 artigos, apenas 4 foram realizados no Brasil, sendo a maioria internacional, o que implica em barreiras de idioma e características socioculturais, além de demonstrar que, no geral, são poucos os estudos dedicados à saúde mental de trabalhadores. Concomitante a isto, foi identificado a falta de pesquisas direcionadas a outros profissionais de setores essenciais, como funcionários de supermercados, farmácias, postos de gasolina e bancos, dentre outros que trabalham diretamente com o atendimento as pessoas; bem como, de profissionais que lidam diretamente com a morte pelo COVID-19 e outros agravos em saúde em contexto pandêmico, como os sepultadores.

Entende-se que, assim como apontado por Lu et al. (2020), os profissionais de saúde, ao vivenciarem de perto a escassez de equipamentos, frustação com os resultados e o descontrole da pandemia, manifestam maior tendência ao sofrimento mental, tal fato que é observado em sua própria pesquisa, no qual a equipe médica apresentou um nível de ansiedade 14,2\% maior do que a classe administrativa, embora esses dados não anulem a necessidade de se pensar a saúde psíquica de outras classes trabalhadoras que ao seu modo enfrentam a pandemia da COVID-19.

Sendo assim, ressalta-se a possiblidade de que grande parte das medidas e estratégias aqui elencadas possam ser adaptadas e direcionadas a trabalhadores de outros setores, havendo espaço para o desenvolvimento de novos procedimentos.

\section{Conclusão}

Diante da crise humanitária, social e econômica gerada pela pandemia da COVID-19 e os impactos na saúde mental dos trabalhadores, em especial os profissionais de saúde que neste momento estão trabaIhando na linha de frente ao combate do vírus, buscou-se com este trabalho sistematizar as principais medidas recomendadas e aplicadas para auxiliar na utilização de recursos por parte dos trabalhadores para enfrentar a emergência em saúde mental gerada pelo contexto atual.

Entre as principais medidas de prevenção ao sofrimento psíquico encontradas estão: estabelecimento de turnos rotativos, estabelecimento de descansos regulares, realização de treinamento de pessoal, além de identificação precoce dos sinais e sintomas de sofrimento psíquico. Embora neste aspecto existam ações desenvolvidas por estância governamental e profissionais de saúde mental, as elencadas são de responsabilidade das organizações.

Já dentre as medidas de promoção a saúde mental mais citadas, estão: fornecimento de apoio psicológico aos profissionais; identificação de necessidades e preocupações; psicoeducação a fim de promover cuidados a saúde mental; realização de planos de atendimento psíquico e aconselhamento psicológico; gerenciamento eficiente de crise e proporcionar um clima organizacional saudável. A execução destas medidas está relacionada em sua maioria aos profissionais de saúde mental.

No que se refere as estratégias e intervenções psicológicas encontradas, as principais são: estratégias de autocuidado; fortalecimento das redes de apoio por meio de telefonemas, mensagens de texto e áudios; exercícios físicos e nutrição. $\mathrm{E}$, dos instrumentos mais utilizados para identificação de sofrimento psíquico e adoecimento mental estão: Transtorno de Ansiedade Generalizada (GAD-7); Escala de Ansiedade de Hamilton (HAMA); Escala de Depressão de Hamilton (HAMD); Escala de Ansiedade e Autoavaliação (SAS). 
Assim, através do mapeamento dessas estratégias tornou-se possível organizar em um único local os recursos que estão sendo empregados com vista a promoção e prevenção da saúde mental dos trabaIhadores, facilitando a busca dessas informações, observando que boa parte dos materiais disponíveis não estão em língua portuguesa. Dito isso, ao reunir em um único espaço as técnicas e práticas direcionadas a saúde psíquica, pretendemos otimizar o acesso dessas possibilidades as psicólogas e psicólogos que atuam no ambiente organizacional, bem como em outras áreas, pois, observamos que as práticas podem ir além do âmbito hospitalar, podendo beneficiar trabalhadores de diversos setores.

Por fim, a limitação deste estudo encontra-se no fato das produções, em sua maioria, contemplarem apenas o ambiente profissional hospitalar e as atividades laborais decorrentes desse campo. Além disso, é válido salientar a necessidade da ampliação de estudos no âmbito da saúde mental dos trabalhadores durante a pandemia de coronavírus instalada em todo o mundo, principalmente, no que se refere a abordagem de estratégias de enfrentamento, bem como prevenção e promoção de saúde mental, que sejam destinadas a todas as áreas. Enquanto recomendação, coloca-se a importância de pesquisar sobre a saúde mental dos profissionais que exercem atividades essenciais tanto durante a pandemia quanto no pós-pandemia, assim como, faz-se necessário trabalhos nacionais que coloquem em ação as medidas aqui elencadas para que se conheça sua eficácia na realidade dos profissionais brasileiros.

\section{Agradecimentos}

Agradecemos à profa. Ms. Rebeca Barbosa Nascimento e Rhaissa Desiree Barbosa de Morais pelo seu tempo dedicado para a realização da revisão e tradução do resumo e do título para a língua inglesa da melhor maneira possível.

\section{Contribuições dos autores}

Nascimento RB, Vieira ES, Araújo IFL e Oliveira ACA realizaram a pesquisa integrativa, extração e discussão de dados, assim como a redação do artigo. Araújo RLMS revisou criticamente o artigo e contribuiu com a redação do artigo científico.

\section{Conflitos de interesses}

Nenhum conflito financeiro, legal ou político envolvendo terceiros (governo, empresas e fundações privadas, etc.) foi declarado para nenhum aspecto do trabalho submetido (incluindo, mas não se limitando a subvenções e financiamentos, participação em conselho consultivo, desenho de estudo, preparação de manuscrito, análise estatística, etc.).

\section{Referências}

Almaguer, A. C., Alvarez, A. K. G., \& Santos, E. Z. (2020). Gestión de seguridad psicológica del personal sanitario en situaciones de emergencia por COVID-19 en el contexto hospitalario o de aislamiento [Gestão da segurança psicológica do pessoal de saúde em situações de emergência devido ao COVID-19 em contexto hospitalar ou de isolamento]. Revista Cubana de Enfermería, 36(2). http://dx.doi. org/10.1590/scielopreprints.252

Blake, H., Bermingham, F., Johnson, G., \& Tabner, A. (2020). Mitigating the Psychological Impact of COVID-19 on Healthcare Workers: A Digital Learning Package [Mitigando o impacto psicológico do COVID-19 em trabalhadores da saúde: um pacote de aprendizagem digital]. International Journal Of Environmental Research And Public Health, 17(9), 2997. https://doi.org/10.3390/ijerph17092997

Bohlken, J., Schömig, F., Lemke, M., Pumberger, M., \& RiedelHeller, S. (2020). COVID-19-Pandemie: Belastungen des medizinischen Personals [Pandemia de COVID-19: estresse na equipe médica]. Psychiatrische Praxis, 47(04), 190-197. https://dx.doi.org/10.1055\%2Fa-1159-5551

Chen, Q., Liang, M., Li, Y., Guo, J., Fei, D., Wang, L., He, L., Sheng, C., Cai, Y., Li, X., Wang, J., \& Zhang, Z. (2020). Mental health care for medical staff in China during the COVID-19 outbreak [Cuidados de saúde mental para equipes médicas na China durante o surto de COVID-19]. The Lancet Psychiatry, 7(4), e15-e16. https://doi.org/10.1016/ S2215-0366(20)30078-X

Chersich, M. F., Gray, G., Fairlie, L., Eichbaum, Q., Mayhew, S., Allwood, B., English, R., Scorgie, F., Luchters, S., Simpson, G., Haghighi, M. M., Pham, M. D., \& Rees, H. (2020). COVID-19 in Africa: care and protection for frontline healthcare workers [COVID-19 na África: cuidado e proteção para profissionais de saúde da linha de frente]. Globalization And Health, 16(1). https://doi.org/10.1186/ s12992-020-00574-3

Costa, F, B. (2020). A saúde mental em meio à pandemia covid-19. Secretaria de Saúde do Distrito Federal. http:// www.saude.df.gov.br/wp-conteudo/uploads/2018/03/ Nota-Informativa-A-Sa\%C3\%BAde-Mental-e-a-Pandemiade-COVID19-poss\%C3\%ADveis-impactos-e-dicas-degerenciamento-para-a-popula\%C3\%A7\%C3\%A3o-geral.pdf 
Fiho, J. M. J., Assunção, A. Á., Algranti, E., Garcia, E. G., Saito, C. A., \& Maeno, M. (2020). A saúde do trabalhador e o enfrentamento da COVID-19. Revista Brasileira de Saúde Ocupacional, 45. http://dx.doi.org/10.1590/23176369ed0000120

Folkman, S. (2012). Stress, Health, and Coping: synthesis, commentary, and future directions [Estresse, saúde e enfrentamento: síntese, comentários e direções futuras]. Oxford University Press. http://dx.doi.org/10.1093/ oxfordhb/9780195375343.013.0022

Guan, W., Ni, Z., Hu, Y., Liang, W., Ou, C., He, J., Liu, L. Shan, H., Lei, C., Hui, D.S. C., Du, B., Li, L., Zeng, G., Yuen, K., Chen, R., Tang, C., Wang, T., Chen, P., Xiang, J., ... Zhong, N. (2020). Clinical Characteristics of Coronavirus Disease 2019 in China [Características clínicas da doença por coronavírus 2019 na China]. New England Journal of Medicine, 382, 1708172. http://dx.doi.org/10.1056/NEJMoa2002032

Greenberg, N., Docherty, M., Gnanapragasam, S., \& Wessely, S. (2020). Managing mental health challenges faced by healthcare workers during covid-19 pandemic [Gerenciando os desafios de saúde mental enfrentados pelos profissionais de saúde durante a pandemia covid-19]. BMJ, 368, m1211. https://doi.org/10.1136/bmj. m1211

Ho, C. S., Chee, C. Y., \& Ho, R. C. (2020). Mental Health Strategies to Combat the Psychological Impact of COVID-19 Beyond Paranoia and Panic [Estratégias de saúde mental para combater o impacto psicológico do COVID-19 além da paranóia e do pânico]. Annals of the Academy of Medicine, Singapore, 49(3), 155-160. https://pubmed.ncbi.nlm.nih. gov/32200399/

Huang, C., Wang, Y., Li, X., Ren, L., Zhao, J., Hu, Y., Zhang, L., Fan, G., Xu, J., Gu, X., Cheng, Z., Yu, T., Xia, J., Wei, Y., Wu, W., Xie, X., Yin, W., We, W., Xie, X., ... Gu, X. (2020). Clinical features of patients infected with 2019 novel coronavirus in Wuhan, China [Características clínicas de pacientes infectados com novo coronavírus de 2019 em Wuhan, China]. The Lancet, 395(10223), 497-506. http://dx.doi.org/10.1016/s01406736(20)30183-5

Huang, J. Z., Han, M. F., Luo, T. D., Ren, A. K., \& Zhou, X. P. (2020). Mental Health Survey of Medical Staff in a Tertiary Infectious Disease Hospital for COVID-19 [Pesquisa de Saúde Mental da Equipe Médica em um Hospital Terciário de Doenças Infecciosas para COVID-19]. Chinese journal of industrial hygiene and occupational diseases, 38(3), 192-195. https://doi.org/10.3760/cma.j.cn121094-20200219-00063
Kang, L., Li, Y., Hu, S., Chen, M., Yang, C., Yang, B. X., Wang, Y., Hu, J., Lai, J., Ma, X., Chen, J., Guan, L., Wang, G., \& Liu, Z. (2020). The mental health of medical workers in Wuhan, China dealing with the 2019 novel coronavirus [A saúde mental dos trabalhadores médicos em Wuhan, China, lidando com o novo coronavírus de 2019]. The Lancet Psychiatry, 7(3), 14. http://dx.doi.org/10.1016/s2215-0366(20)30047-x

Lai, J., Ma, S., Wang, Y., Cai, Z., Hu, J., Wei, N., Wu, J., Du, H., Chen, T., Li, R., Tan, Hu., Kang, L., Yao, L., Huang, M., Wang, H., Wang, G., Liu, Z., \& Hu, S. (2020). Factors Associated With Mental Health Outcomes Among Health Care Workers Exposed to Coronavirus Disease 2019 [Fatores associados aos resultados de saúde mental entre profissionais de saúde expostos à doença do coronavírus em 2019]. JAMA Network Open, 3(3), e203976. http://dx.doi.org/10.1001/ jamanetworkopen.2020.3976

Lazarus, R, S., \& Folkman, S. (1984). Stress, appraisal, and coping [Estresse, avaliação e enfrentamento]. Springer.

Lu, W., Wang, H., Lin, Y., \& Li, L. (2020). Psychological status of medical workforce during the COVID-19 pandemic: A cross-sectional study [Status psicológico da força de trabalho médica durante a pandemia de COVID-19: um estudo transversal]. Psychiatry Research, 288, 112936. https://doi.org/10.1016/j.psychres.2020.112936

Ministério da Saúde. (2020). Sobre a doença: o que é o Covid?. Gov.br. https://coronavirus.saude.gov.br/sobre-adoenca\#o-que-e-covid

Rolim Neto, M., Almeida, H. G., Esmeraldo, J. D., Nobre, C. B., Pinheiro, W. R., Oliveira, C. R. T., Souza, I. C., Lima, O. M. M. L., Lima, N. N. R., Moreira, M. M., Lima, C. K. T., Gonçalves Júnior, J., \& Silva, C. (2020). When health professionals look death in the eye: the mental health of professionals who deal daily with the 2019 coronavirus outbreak [Quando o profissional de saúde olha a morte nos olhos: a saúde mental dos profissionais que lidam diariamente com o surto de coronavírus de 2019]. Psychiatry research, 288, 112972. https://doi.org/10.1016/j.psychres.2020.112972

Oliveira, W., Oliveira-Cardoso, É., Silva, J., \& Santos, M. (2020). Impactos psicológicos e ocupacionais das sucessivas ondas recentes de pandemias em profissionais da saúde: revisão integrativa e lições aprendidas. Estudos de Psicologia (Campinas), 37, e200066. https://dx.doi. org/10.1590/1982-0275202037e200066

Ornell, F., Schuch, J. B., Sordi, A. O., \& Kessler, F. H. P. (2020). "Pandemic fear" and COVID-19: mental health burden and strategies ["Medo pandêmico" e COVID-19: carga e estratégias de saúde mental]. Brazilian Journal of Psychiatry, 42(3), 232-235. https://doi.org/10.1590/15164446-2020-0008 
Ornell, F., Halpern, S, C., Kessler, F, H, P., \& Narvaez, J, C. (2020). The impact of the COVID-19 pandemic on the mental health of healthcare professionals [O impacto da pandemia COVID-19 na saúde mental dos profissionais de saúde]. Cadernos de Saúde Pública, 36(4), e00063520. https://doi.org/10.1590/0102-311×00063520

Petzold, M., Plag, J., \& Ströhle, A. (2020). Umgang mit psychischer Belastung bei Gesundheitsfachkräften im Rahmen der Covid-19-Pandemie [Lidando com o estresse psicológico entre profissionais de saúde no contexto da pandemia de Covid 19]. Nervenarzt, 91(5), 417-421. https://dx.doi. org/10.1007\%2Fs00115-020-00905-0

Ramos, F. P., Enumo, S. R. F., \& Paula K. M. P. (2015). Teoria Motivacional do Coping: uma proposta desenvolvimentista de análise do enfrentamento do estresse. Estudos de Psicologia, 32(2): 269-279. https://doi.org/10.1590/0103166X2015000200011

Schmidt, B., Crepaldi, M, A., Bolze, S. D. A., Neiva-Silva, L. \& Demenech, L, M. (2020). Saúde mental e intervenções psicológicas diante da pandemia do novo coronavírus (COVID-19). Estudos de Psicologia (Campinas), 37, e200063. https://doi.org/10.1590/1982-0275202037e200063

Secretaria de Estado de Saúde do Mato Grosso do Sul. (2019). Boletim Informativo em Saúde do Trabalhador 2019. saude.ms. https://www.vs.saude.ms.gov.br/boletiminformativo-em-saude-do-trabalhador-2019-2/

Souza, M. T., Silva, M. D., \& Carvalho, R. (2010). Revisão integrativa: o que é e como fazer. Einstein (São Paulo), 8(1), 102-106. https://doi.org/10.1590/s1679-45082010rw1134

Souza, W. F. (2013). Transtornos mentais e comportamentais relacionados ao trabalho: o que a psicologia tem a dizer e a contribuir para a saúde de quem trabalha? Fractal: Revista de Psicologia, 25(1), 99-108. http://dx.doi. org/10.1590/s1984-02922013000100007
Stone, L. (2020). Coping during a pandemic [Lidando com uma pandemia]. Australian Journal of General Pratice, 49. https:// doi.org/10.31128/AJGPCOVID-19

Sun, N., Wei, L., Shi, S., Jiao, D., Song, R., Ma, L., Wang, H., Wang, C., Wang, Z., You, Y., Liu, S., \& Wang, H. (2020). A qualitative study on the psychological experience of caregivers of COVID-19 patients [Um estudo qualitativo sobre a experiência psicológica de cuidadores de pacientes com COVID-19]. American journal of infection control, 48(6), 592-598. https://doi.org/10.1016/j.ajic.2020.03.018

World Health Organization. (2000). Mental health and work: Impact, issues and good practices [Saúde mental e trabalho: impacto, problemas e boas práticas]. https://www.who. int/mental health/media/en/712.pdf

Wu, K., \& Wei, X. (2020). Analysis of Psychological and Sleep Status and Exercise Rehabilitation of Front-Line Clinical Staff in the Fight Against COVID-19 in China [Análise do estado psicológico e do sono e reabilitação por exercício do pessoal clínico da linha de frente na luta contra a COVID-19 na China]. Medical science monitor basic research, 26, e924085. https://doi.org/10.12659/MSMBR.924085

Yahya, A. S., Khawaja, S., \& Chukwuma, J. (2020). The Impact of COVID-19 in Psychiatry [O impacto do COVID-19 na psiquiatria]. The primary care companion for CNS disorders, 22(2), 20102627. https://doi.org/10.4088/PCC.20102627

Zhang, C., Yang, L., Liu, S., Ma, S., Wang, Y., Cai, Z., Du, H., Li, R., Kang, L., Su, M., Zhang, J., Liu, Z., \& Zhang, B. (2020). Survey of Insomnia and Related Social Psychological Factors Among Medical Staff Involved in the 2019 Novel Coronavirus Disease Outbreak [Pesquisa de insônia e fatores psicológicos sociais relacionados entre a equipe médica envolvida no novo surto de doença por coronavírus de 2019]. Frontiers in psychiatry, 11, 306. https://doi.org/10.3389/fpsyt.2020.00306 